\title{
Physical activity, calcium intake, and bone mineral content in children in The Netherlands
}

Marjolein F Q VandenBergh, Stella A DeMan, Jacqueline C M Witteman, Albert Hofman, Willem Th Trouerbach, Diederick E Grobbee

\begin{abstract}
Study objective - To examine the relation between physical activity, calcium intake, and bone mineral content in children.

Design - Population based, cross sectional study.

Setting - Primary schools in Zoetermeer, The Netherlands.

Participants - Altogether 1359 Dutch boys and girls, aged 7 to 11 years (response rate $\mathbf{8 8 \% )}$.
\end{abstract}

Measurements - Bone mineral content was measured by quantitative roentgen microdensitometry of the midphalanx of the second digit at the diaphyseal and metaphyseal site. Maximal exercise testing, according to the Bruce treadmill protocol, was used to assess physical fitness. $\mathrm{Ha}$ bitual physical activity was assessed by use of a questionnaire on physical activities. Daily calcium intake from dairy products was estimated by use of a semiquantitative food frequency questionnaire.

Main results - Bone mineral content in boys was not linearly associated with physical fitness after adjustments for differences in height, body weight, chronological age, and skeletal age. In girls a linear association was found at the metaphyseal site only. When extreme groups were compared, bone mineral content was found to be higher in "high fitness children" (upper decile) than "low fitness children" (lowest decile), with statistical significance reached in boys only. When analyses were performed in subgroups of skeletal age, a clear linear relation between physical fitness and bone mineral content was seen in the mature subgroup in both boys and girls. No linear association was found between habitual physical activity and bone mineral content, while the results in extreme groups (that is, upper versus lowest decile) and in subgroups of skeletal age were comparable to those on physical fitness in boys only. No association was found between daily calcium intake and bone mineral content in this age group. Conclusions - This cross sectional study in children aged 7 to 11 years suggests that an increased bone mineral content is found only in those with a high level of physical activity. This association is most pronounced in the more mature children. No evidence was found for an association between daily calcium intake and bone mineral content in childhood.

(f Epidemiol Community Health 1995;49:299-304)
Osteoporosis is a major public health problem in the western world. The amount of bone achieved at maturity has been suggested as an important determinant of osteoporosis. ${ }^{1-4}$ Peak bone mineral content results from the accumulation of bone during growth and maturation. Factors that exert their influence on the skeleton in the years preceding skeletal maturity may therefore be important in determining peak bone mineral content.

Several studies have been performed on determinants of bone mineral content during growth. Sex, race, chronological age, height, body weight, skeletal age, and pubertal stage have been found to be associated with bone mineral content during childhood and puberty. ${ }^{5-11}$ Physical activity and calcium intake have been studied intensively as possible determinants of adult bone mineral content and osteoporosis. Physical activity has been found to be one of the determinants of adult bone mineral content and of the development of osteoporosis. ${ }^{12-18}$ Studies on calcium intake and adult bone mineral content suggest that a habitual high calcium intake may prevent the development of osteoporosis by increasing adult peak bone mass, rather than reducing the rate of bone loss with ageing. ${ }^{1719-22}$ Recent studies have shown an increased rate in gain of bone mineral content with calcium supplementation in children. ${ }^{23-25}$

To examine the relation between physical activity, calcium intake, and bone mineral content during childhood, a cross sectional study was performed in a population of 1359 Dutch children aged 7 to 11 years.

\section{Methods}

POPULATION

Between March 1987 and June 1989, 1558 schoolchildren, aged 6.8 to 10.7 years, participated in a study on the relation between physical fitness and cardiovascular risk factors in childhood. They were all 3 rd and 4 th graders of a random sample of 28 of 44 primary schools in the Dutch town of Zoetermeer. The response rate was $88 \%$. Details of the study have been reported previously. ${ }^{26}$ In addition to cardiovascular risk factors, bone mineral content was measured. Because of possible racial differences in skeletal development and peak bone mass, ${ }^{9}$ only data of children from Dutch origin were used in the present analyses ( 653 boys, 706 girls).

MEASUREMENTS

Radiographs (3M GT $x$ ray films and Trimax alpha 2 intensifying screens) of the left hand 
were made from a distance of $1.00 \mathrm{~m}$ (Philips $x$ ray unit (Elinax 90/20) $43 \mathrm{kV}, 0.7 \mathrm{~s}$ and $20 \mathrm{~mA}$ ). A linear aluminium wedge of $0-12 \mathrm{~mm}$ was exposed simultaneously. Quantitative roentgen microdensitometry of the midphalanx of the second digit was performed using a standard posterior-anterior radiograph of the hand and a supplementary lateral radiograph of the index finger. Because the two radiographs were made in planes perpendicular to each other, it was possible to estimate the bone mineral content per unit volume of bone. A detailed description of the scanning procedure has been published previously. ${ }^{27}$ Measurements were made at midlength (diaphysis) and at $25 \%$ of the length from the proximal end of the phalanx (metaphysis). The diaphyseal region is a relatively uniform shaft of cortical bone, whereas the metaphyseal region contains more trabecular bone. Results are expressed as $\mathrm{mm}$ $\mathrm{Al}$ equivalent $/ \mathrm{mm}^{3}$. Bone mineral content measurements were reproducible with a coefficient of variation of less then $2 \%$, as measured in adults. ${ }^{27}$ Bone mineral content data were not available for 154 children ( 68 boys), who had moved their hand during the $x$ ray exposure.

Physical fitness, defined as maximal aerobic capacity, was determined directly by measuring oxygen uptake during a maximal exercise test, according to the Bruce treadmill protocol. ${ }^{28}$ The criteria for reaching maximal oxygen uptake were levelling off of oxygen uptake (that is, no increase or less than $2 \mathrm{ml} . \mathrm{kg}^{-1} \cdot \mathrm{min}^{-1}$ ) and/or levelling off of the heart rate despite an increased workload. Data of 188 children ( 94 boys) were excluded from the analysis because they either did not follow the protocol correctly or did not meet the criteria for reaching maximal oxygen uptake. Mean values of bone mineral content were comparable for children who did and who did not reach their maximal aerobic capacity.

A questionnaire on physical activities during the three preceding months was completed by one of the parents of the child. ${ }^{29}$ Activities were classified according to their energy expenditure, independent of body sixe, by using the ratio between work metabolic rate and basal metabolic rate (metabolic equivalent, MET). ${ }^{30}$ Questions were limited to activities with a minimal intensity level of approximately four times the basal metabolic rate ( 4 METs) which equals walking at a speed of approximately $5 \mathrm{~km} / \mathrm{h}$. Subsequently, the scored activities were subdivided into three levels of intensity - light, medium, and heavy activities - corresponding to relative energy expenditures of 4-7 METs, 7-10 METs, and 10 METs or more respectively. The energy expenditure per week, above a level of 4 METs and expressed as multiples of the basal metabolic rate, was estimated by multiplying the time spent per level of intensity by a fixed value for the relative energy expenditure at the level - that is $5 \frac{1}{2}$ METs for the light activities, $8 \frac{1}{2}$ METs for the medium heavy activities, and $11 \frac{1}{2}$ METs for the heavy activities.

A semiquantitative food frequency questionnaire was used to assess the daily calcium intake from dairy products, ${ }^{31}$ which covers approximately $80 \%$ of the total dietary calcium intake. One of the parents of the child was asked to estimate the daily consumption of dairy products during the three preceding months by questioning about the type and frequency of dairy products in the diet, and the average size of servings. The average daily calcium intake from dairy products was calculated by use of the Dutch Food Composition Table. ${ }^{32}$

Radiographs of the left hand were used to determine skeletal age. The sum of maturity scores of 13 bones, comprising radius, ulna and short finger bones (RUS score) was used for the standardisation of skeletal age according to the method of Tanner. ${ }^{33}$ All radiographs were read by one trained paramedical assistant. Skeletal age could not be assessed in 83 children (34 boys). Mean bone mineral content values of those children were not materially different from values in those in which skeletal age assessment was possible. According to their skeletal age, the children were divided into two groups. A maturity score of 300 , a value beyond which maturity scores increase at faster rates, was used as cut off point. This score corresponds with a skeletal age of approximately 10.0 years in boys and approximately 7.0 years in girls, reflecting the fact that girls mature at a younger age than boys. ${ }^{33}$ Height and body weight were measured wearing indoor clothing and no shoes.

Table 1 General characteristics of the study population

\begin{tabular}{|c|c|c|c|c|c|c|}
\hline & \multicolumn{3}{|c|}{ Boys $(n=653)$} & \multicolumn{3}{|c|}{ Girls $(n=706)$} \\
\hline & Mean & $(S D)$ & $(I Q R)$ & Mean & $(S D)$ & $(I Q R)$ \\
\hline \multirow{11}{*}{ 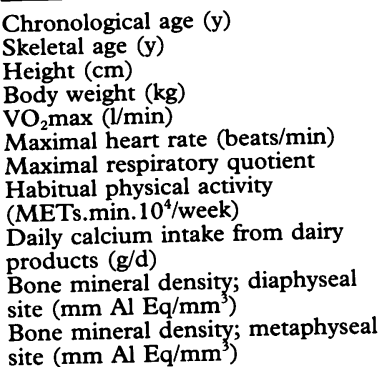 } & $8 \cdot 4$ & $(0 \cdot 71)$ & $(7 \cdot 8-8 \cdot 9)$ & $8 \cdot 4$ & $(0.67)$ & $(7 \cdot 8-8 \cdot 9)$ \\
\hline & $7 \cdot 9$ & $(1 \cdot 39)$ & $(7 \cdot 0-8 \cdot 7)$ & $8 \cdot 3$ & $(1 \cdot 34)$ & $(7 \cdot 3-9 \cdot 3)$ \\
\hline & 134 & $(6 \cdot 7)$ & $(129-138)$ & 134 & $(6 \cdot 6)$ & $(129-137)$ \\
\hline & $28 \cdot 6$ & $(4 \cdot 36)$ & $(25 \cdot 0-30 \cdot 0)$ & $28 \cdot 8$ & $(4 \cdot 73)$ & $(25 \cdot 0-31 \cdot 0)$ \\
\hline & 1.41 & $(0 \cdot 274)$ & $(1.24-1.59)$ & $1 \cdot 27$ & $(0 \cdot 237)$ & $(1 \cdot 12-1 \cdot 40)$ \\
\hline & 205 & $(8 \cdot 5)$ & $\begin{array}{l}(199-210) \\
(1 \cdot 08-1 \cdot 21)\end{array}$ & 208 & $\begin{array}{l}(8 \cdot 9) \\
(0 \cdot 10)\end{array}$ & $\begin{array}{l}(200-214) \\
(1 \cdot 10-1 \cdot 24)\end{array}$ \\
\hline & $1 \cdot 1$ & $(0 \cdot 10)$ & & & & \\
\hline & 0.44 & $(0 \cdot 202)$ & $(0.30-0.53)$ & 0.37 & $(0 \cdot 174)$ & $(0.25-0.44)$ \\
\hline & $1 \cdot 3$ & $(0 \cdot 44)$ & $(1 \cdot 0-1 \cdot 5)$ & $1 \cdot 2$ & $(0 \cdot 43)$ & $(0 \cdot 9-1 \cdot 4)$ \\
\hline & 0.360 & $(0.038)$ & $(0.335-0.383)$ & 0.369 & $(0.037)$ & $(0.344-0.395)$ \\
\hline & $0 \cdot 259$ & $(0.026)$ & $(0 \cdot 241-0 \cdot 274)$ & $0 \cdot 265$ & $(0.027)$ & $(0.246-0.282)$ \\
\hline
\end{tabular}

$\mathrm{IQR}=$ interquartile range. 
Table 2 Coefficients of linear regression ( $\beta$ ) of bone mineral content on physical fitness, habitual physical activity and daily calcium intake

\begin{tabular}{|c|c|c|c|c|c|c|c|c|}
\hline & \multirow[t]{2}{*}{$N o^{*}$} & \multicolumn{4}{|c|}{ Diaphyseal site } & \multicolumn{3}{|c|}{ Metaphyseal site } \\
\hline & & $\beta$ & $(95 \% C I)$ & & $p$ & $\beta$ & $(95 \% C I)$ & $p$ \\
\hline \multicolumn{9}{|c|}{ Boys } \\
\hline \multicolumn{9}{|c|}{ Physical fitness $(1 / \mathrm{min})$} \\
\hline $\begin{array}{l}\text { Unadjusted } \\
\text { Adjusted } t\end{array}$ & $\begin{array}{l}504 \\
499\end{array}$ & $\begin{array}{r}0.014 \\
-0.006\end{array}$ & $\begin{array}{l}(-0.001, \\
(-0.028,\end{array}$ & $\begin{array}{l}0 \cdot 028) \\
0.016)\end{array}$ & $\begin{array}{l}0.07 \\
0.57\end{array}$ & $\begin{array}{l}0.014 \\
0.005\end{array}$ & 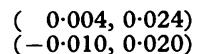 & $\begin{array}{l}0.01 \\
0.48\end{array}$ \\
\hline \multicolumn{9}{|c|}{ Habitual physical activity (METs.min. $10^{4} / \mathrm{wk}$ ) } \\
\hline $\begin{array}{l}\text { Unadjusted } \\
\text { Adjusted } †\end{array}$ & $\begin{array}{l}585 \\
579\end{array}$ & $\begin{array}{l}0.011 \\
0.010\end{array}$ & $\begin{array}{l}(-0.003 \\
(-0.005\end{array}$ & $\begin{array}{l}0.025) \\
0.025)\end{array}$ & $\begin{array}{l}0 \cdot 16 \\
0 \cdot 19\end{array}$ & $\begin{array}{l}0.008 \\
0.009\end{array}$ & $\begin{array}{l}(-0.002,0.019) \\
(-0.002,0.019)\end{array}$ & $\begin{array}{l}0 \cdot 10 \\
0 \cdot 10\end{array}$ \\
\hline \multicolumn{9}{|c|}{ Daily calcium intake from dairy products $(\mathrm{g} / \mathrm{d})$} \\
\hline $\begin{array}{l}\text { Unadjusted } \\
\text { Adjusted } \dagger\end{array}$ & $\begin{array}{l}585 \\
579\end{array}$ & $\begin{array}{l}0.005 \\
0.005\end{array}$ & $\begin{array}{l}(-0.002, \\
(-0.003\end{array}$ & $\begin{array}{l}0.013) \\
0.012)\end{array}$ & $\begin{array}{l}0 \cdot 14 \\
0 \cdot 20\end{array}$ & $\begin{array}{l}0.003 \\
0.003\end{array}$ & $\begin{array}{l}(-0.002,0.008) \\
(-0.002,0.007)\end{array}$ & $\begin{array}{l}0 \cdot 23 \\
0 \cdot 31\end{array}$ \\
\hline \multicolumn{9}{|c|}{ Girls } \\
\hline $\begin{array}{l}\text { Unadjusted } \\
\text { Adjusted } \dagger\end{array}$ & $\begin{array}{r}538 \\
529\end{array}$ & $\begin{array}{l}0.024 \\
0.015\end{array}$ & $\begin{array}{r}0.008 \\
(-0.008\end{array}$ & $\begin{array}{l}0.039) \\
0.038)\end{array}$ & $\begin{array}{c}<0.001 \\
0.20\end{array}$ & $\begin{array}{l}0.022 \\
0.019\end{array}$ & 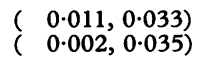 & $\begin{array}{c}<0.001 \\
0.02\end{array}$ \\
\hline \multicolumn{9}{|c|}{ Habitual physical activity (METs.min. $10^{4} / \mathrm{wk}$ ) } \\
\hline $\begin{array}{l}\text { Unadjusted } \\
\text { Adjusted } †\end{array}$ & $\begin{array}{l}620 \\
610\end{array}$ & $\begin{array}{l}-0.019 \\
-0.019\end{array}$ & $\begin{array}{l}(-0.036 \\
(-0.035\end{array}$ & $\begin{array}{l}-0.003) \\
-0.002)\end{array}$ & $\begin{array}{l}0.02 \\
0.03\end{array}$ & $\begin{array}{l}-0.009 \\
-0.009\end{array}$ & $\begin{array}{l}(-0.002,0.003) \\
(-0.021,0.003)\end{array}$ & $\begin{array}{l}0 \cdot 13 \\
0 \cdot 13\end{array}$ \\
\hline \multicolumn{9}{|c|}{ Daily calcium intake from dairy products $(\mathrm{g} / \mathrm{d})$} \\
\hline $\begin{array}{l}\text { Unadjusted } \\
\text { Adjusted } †\end{array}$ & $\begin{array}{l}620 \\
610\end{array}$ & $\begin{array}{l}-0.002 \\
-0.002\end{array}$ & $\begin{array}{l}(-0.009 \\
(-0.009\end{array}$ & $\begin{array}{l}0.005) \\
0.005)\end{array}$ & $\begin{array}{l}0.59 \\
0.65\end{array}$ & $\begin{array}{l}-0.003 \\
-0.004\end{array}$ & $\begin{array}{l}(-0.008,0.002) \\
(-0.009,0.001)\end{array}$ & $\begin{array}{l}0 \cdot 11 \\
0 \cdot 19\end{array}$ \\
\hline
\end{tabular}

* Numbers do not always add up to the total number due to missing values.

t Adjusted for differences in height, body weight, chronological age and skeletal age.
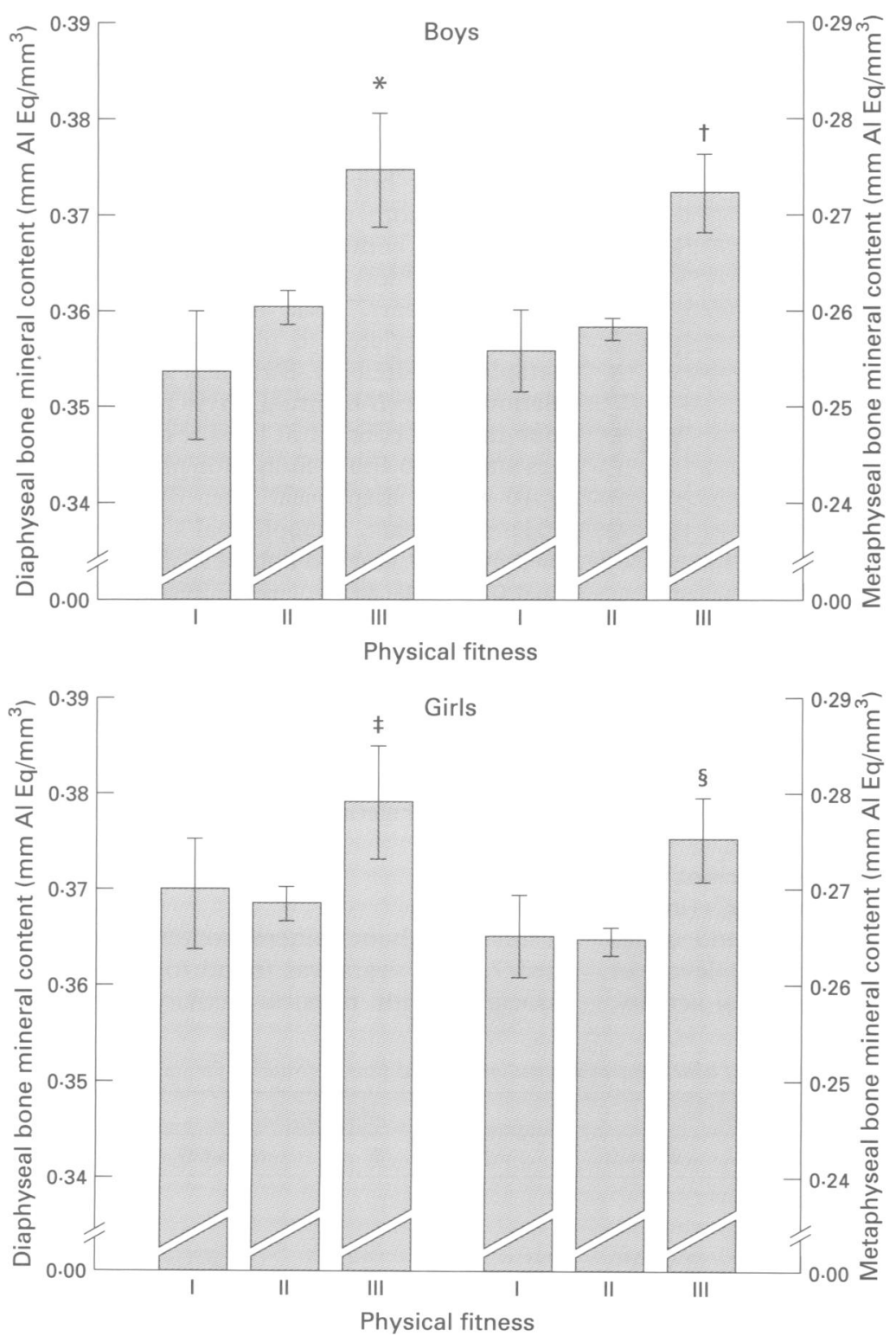

Figure 1 Mean (SEM) bone mineral content in groups with a "low" (lowest decile, I), "middle" (between lowest and upper decile, II), and "high" (upper decile, III) level of physical fitness. Results are adjusted for differences in height, body weight, chronological age, and skeletal age.

${ }^{*} p=0.03$ (III $\left.\vee I\right) ; \dagger p=0.01$ (III $\left.\vee I\right) ; \ddagger p=0.31$ (III $\left.\vee I\right) ; § p=0.13$ (III $\left.\vee I\right)$.
DATA ANALYSIS

Linear regression analyses were performed with bone mineral content as the dependent and, successively, physical fitness, habitual physical activity, and daily calcium intake as the independent variables. Adjustments were made for differences in height, body weight, chronological age and skeletal age, which were considered to be potential confounders. Additionally, mean (SEM) values of bone mineral content were determined for those in the lowest and upper deciles of physical fitness, habitual physical activity and daily calcium intake. Two sided Student's $t$ tests were used to test for differences between the categories. Possible effect modification of the examined relations be skeletal age was examined in stratified analyses.

\section{Results}

Characteristics of the population are shown in table 1. Girls had higher levels of bone mineral content at diaphyseal and metaphyseal sites than boys. Boys had higher levels of physical fitness, habitual physical activity, and daily calcium intake from dairy products. In boys, physical fitness and habitual physical activity were significantly correlated $(r=0.141, p<0.001)$, whereas in girls no correlation was found ( $r=$ $0.015, \mathrm{p}=0.71$ ).

Table 2 shows the unadjusted and adjusted regression coefficients of bone mineral content on physical fitness, habitual physical activity, and daily calcium intake from dairy products. After adjustments had been made for differences in height, body weight, chronological age, and skeletal age, no linear relation between physical fitness and bone mineral content in boys could be found. In girls bone mineral content was related to physical fitness at the metaphyseal site only. Bone mineral content was not linearly related to habitual physical activity in boys. In girls, metaphyseal bone mineral content was not related to habitual physical activity, whereas for diaphyseal bone mineral content an inverse relation was found. For boys and girls no relation was found be- 

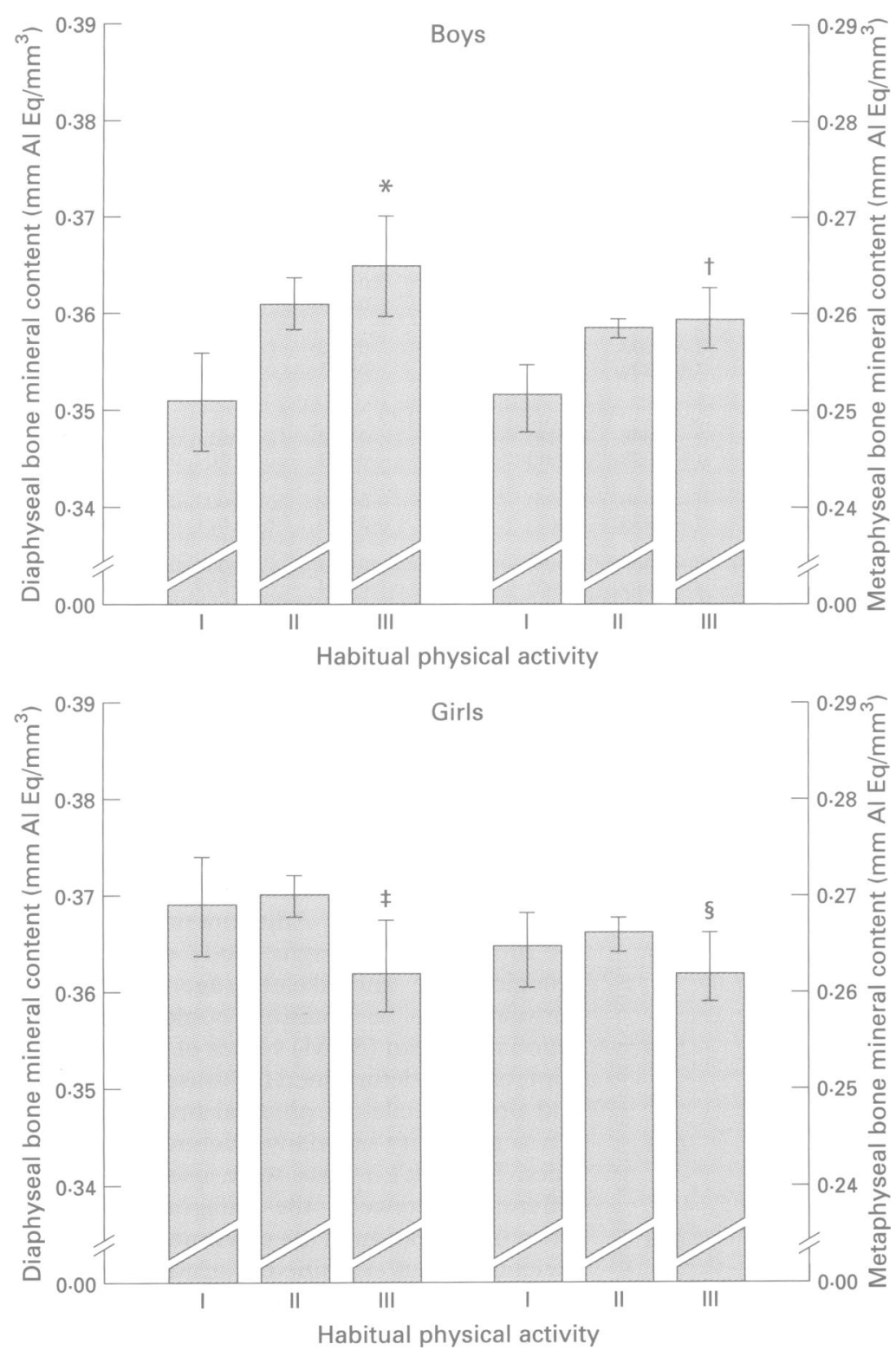

Figure 2 Mean (SEM) bone mineral content in groups with a "low" (lowest decile, I), "middle" (between lowest and upper decile, II), and "high" (upper decile, III) level of habitual physical activity. Results are adjusted for differences in height, body weight, chronological age, and skeletal age.

${ }^{*} p=0.05$ (III $\left.\vee I\right) ; \dagger p=0.08$ (III $\left.\vee I\right) ; \ddagger p=0.31$ (III $\left.\vee I\right) ; \varnothing p=0.72$ (III $\vee I$ ).

tween daily calcium intake and bone mineral content.

Figures 1 and 2 show the mean levels of bone mineral content in relation to "low" (lowest decile), "middle" (between lowest and upper deciles), and "high" (upper decile) levels of physical fitness and habitual physical activity, respectively. Adjustments were made for differences in height, body weight, chronological age, and skeletal age. For boys and girls a higher diaphyseal and metaphyseal bone mineral content was found in the "high fitness group" compared with the "low fitness group", with significant differences in boys only. In boys a higher diaphyseal and metaphyseal bone mineral content was also found in the "high activity group" compared with the "low activity group", but differences were significant at the diaphyseal site only. For girls mean bone mineral content did not significantly differ between the "high" and "low" activity groups. No significant differences in adjusted mean levels of bone mineral content were found when "high" and "low" calcium intake groups were compared, "high" and "low" being defined by the upper and lowest decile of calcium intake.

Table 3 shows the adjusted regression coefficients of bone mineral content on physical fitness for those with a skeletal age above 10.0 years (boys) or 7.0 years (girls), and for those with a skeletal age of 10.0 years or lower (boys) or 7.0 years or lower (girls). No relation between physical fitness and bone mineral content was found for a skeletal age of 10.0 years or lower for boys and 7.0 years or lower for girls. However, for boys with a skeletal age above 10.0 years, both diaphyseal and metaphyseal bone mineral content were found to be related to physical fitness. In girls with a skeletal age above 7.0 years, bone mineral content was significantly related to physical fitness at the metaphyseal site only. Stratified analysis of the relation between habitual physical activity and bone mineral content in boys resulted in findings similar to those found for physical fitness ( $\leq 10$ years, diaphyseal site: $\beta=0.005, p=$ 0.51 ; $\leq 10$ years, metaphyseal site: $\beta=0.005$, $\mathrm{p}=0.30 ;>10$ years, diaphyseal site: $\beta=0.096$, $\mathrm{p}=0.01 ;>10$ years, metaphyseal site: $\beta=$ $0.061, p=0.02$ ). In girls no relation between habitual physical activity and bone mineral content was found either in the less mature or more mature groups. No relation between daily calcium intake from dairy products and bone mineral content was observed after stratification by skeletal age.

\section{Discussion}

In this study bone mineral content in children aged 7 to 11 years was found to be positively associated with physical activity only when

Table 3 Coefficients of linear regression $(\beta)$ of bone mineral content on physical fitness, stratified for skeletal age*

Table 3 Coefficients of linear regression $(\beta)$ of bone mineral content on physical fitness, stratified for skeletal age*

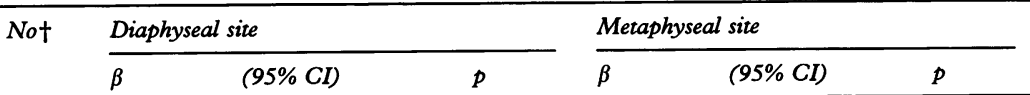

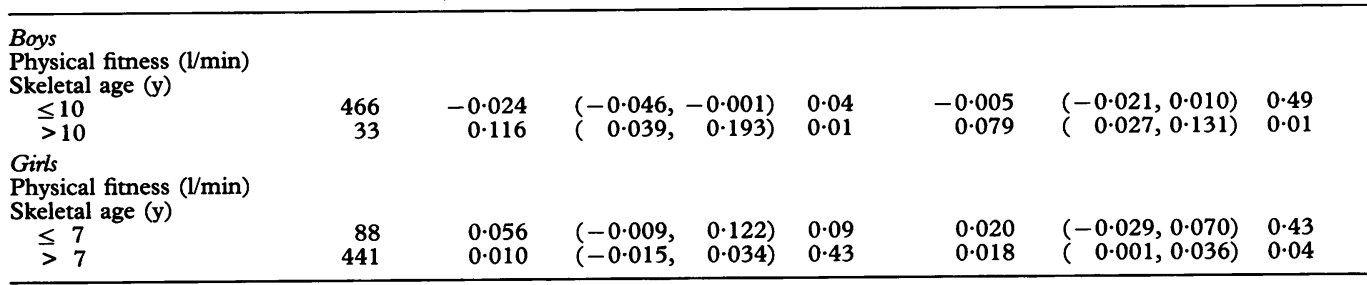

* Adjusted for differences in height, body weight, chronological age and skeletal age.

t Numbers do not always add up to the total number due to missing values.

$\dagger \mathrm{Numbers}$
$\mathrm{CI}=$ confidence intervals. 
"high fitness" children were compared with "low fitness" children - "high" and "low" being defined by upper and lowest deciles of physical fitness. In the more mature children, however, a clear linear relation between physical fitness and bone mineral content was found for both boys and girls. The results on habitual physical activity in boys were similar to those on physical fitness, whereas in girls no association was found between habitual physical activity and bone mineral content. This study does not provide evidence for an association between daily calcium intake from dairy products and bone mineral content in childhood.

Several techniques are available for the accurate assessment of bone mineral content. The methods most frequently used are single photonabsorptiometry of the radius, dual photonabsorptiometry of the vertebral column, and radiographs of a peripheral bone, for example metacarpal, radius, or ulna. These methods do not have the possibility of taking the third dimension of an individual bone into account. The method of quantitative microdensitometry, as used in the present study, provides compensation for the differences in bone size between subjects and for changes in bone size in time. ${ }^{27}$ Another advantage of the quantitative microdensitometry is the relatively low irradiation exposure $\left(2 \cdot 10^{-9} \mathrm{~Sv}^{-1}\right)$. In contrast with studies in adults, in which single site measurements may not be useful, ${ }^{34}$ a recent study observed high correlations for bone mineral content among different bone sites in children, even though the relative amounts of cortical and trabecular bone differed between the different skeletal sites. ${ }^{35}$ This suggests that bone mineral content measurements in children provide comparable information when being performed in either the appendicular skeleton or the lumbar vertebrae.

Physical activity was assessed by measuring physical fitness during a maximal exercise test, and by use of a questionnaire on daily physical activities. It is generally agreed that the best method for maximal exercise testing in children of this age is a treadmill test. ${ }^{36}$ The Bruce treadmill test was used because of its high reproducibility in children. ${ }^{37}$ Although questionnaires on physical activity have been shown to be very practical and relatively reliable epidemiologic measures of habitual physical activity in large adult populations, ${ }^{38}$ the use of a parent administered questionnaire on the child's activities may have limited the accuracy and precision of these activity data. ${ }^{39}$ In adults and postpubertal children, physical fitness, defined as maximal aerobic capacity $\left(\mathrm{VO}_{2} \mathrm{max}\right)$, is known to be associated with the level of habitual physical activity. ${ }^{384041}$ In prepubertal children, however, this association was found in some studies, ${ }^{404243}$ but not in others. ${ }^{4144}$ In a recent study on physical activity in children, physical fitness was found to be associated with the level of habitual physical activity (assessed by use of a questionnaire) in boys only. ${ }^{45}$ The present study confirms this finding. Physical fitness and habitual physical activity were significantly correlated in boys, but not in girls.
Although we do not have a ready explanation for the sex difference in the correlation between physical fitness and habitual physical activity, it may explain the absence of a relation between habitual physical activity and bone mineral content in girls in the present study.

Physical activity has been found to be one of the determinants of adult bone mineral content, the development of osteoporosis and the risk of fractures. ${ }^{12-18}$ The relation between physical activity and bone mineral content in adult women was most clear when "lifetime" physical activity levels were considered rather than "current" activity levels. ${ }^{1517}$ This finding suggests an important role for physical activity habits in enhancing peak bone mineral content, reached at maturity. Physical activity during the formative years may positively affect the distribution of bone, resulting in an increased bone area and a larger peak bone mineral content. Two recent studies on bone mineral content in childhood have found that the increase in bone mineral content with age in children becomes steeper at the time of puberty. ${ }^{1011}$ One might therefore expect that factors influencing bone formation or bone resorption have more impact in late than early childhood. Our finding that an association between physical activity and bone mineral content is predominantly seen in boys and girls with a skeletal age above 10.0 years and 7.0 years respectively, confirms this hypothesis.

Bone mineral content has been found to be associated with the level of "lifetime" dietary calcium intake in both pre- and postmenopausal women, ${ }^{17}{ }^{19}$ whereas "current" calcium intake seemed to have no effect on bone mineral content, postmenopausal bone loss, or the risk of fracture. ${ }^{17-20}$ Moreover, postmenopausal bone density was found to be higher in women who had a high milk consumption during childhood and adolescence than in those who had avoided milk while young. ${ }^{21} 22$ This suggests that a high dietary calcium intake may prevent the development of osteoporosis by increasing adult peak bone mineral content, rather than reducing the rate of ageing bone loss. Recent studies have shown a significant effect of calcium supplementation on bone accretion in children. ${ }^{23-25}$ In this study, however, we could not find an association between calcium intake and bone mineral content. This may be due to the fact that approximately $80 \%$ of the children in this study had a calcium intake which equalled or exceeded the recently suggested threshold values of $1400 \mathrm{mg}$ per day for children of this age. ${ }^{46}$ In the threshold model, bone mineral content is a function of calcium intake only up to the threshold level, and beyond that point further variation in intake has no effect. The dietary history method, used in this study, is considered to provide useful and reproducible information about nutritional intake. ${ }^{47} 48$ The questionnaire used has proved to be valid in Dutch adults. ${ }^{31}$ We cannot, however, exclude the possibility that the use of a questionnaire, which called on the capacity of the parent to remember details of the child's diet over the past three 
months also accounts for the absence of a detectable effect of dietary calcium on bone mineral content.

This study in primary school children suggests that an increased bone mineral content is found only in those with a high level of physical activity. In the more mature children, a linear association between physical activity and bone mineral content was found. Future studies should further investigate whether bone mineral content will be favourably affected by increasing physical activity levels in early and late childhood. No evidence was found for an association between the daily calcium intake from dairy products and bone mineral content during childhood.

We thank the children and parents who participated in this study. We acknowledge Anneke van der Muil-Houwing, $\mathrm{Ria}$ study. We acknowledge Anneke van der Muil-Houwing, Ria Rijneveldshoek, Wilma Verbruggen, Frans Dullemeijer, Theo van der Berg, and the students of the Faculty of Human Movement Sciences, University of Amsterdam (Director Prof
H C G Kemper) for their work at the research centre, and H C G Kemper) for their work at the research centre, and
Andries Zwamborn for his useful comments. We thank $3 \mathrm{M}$ Nederland BV for supplying intensifying screens and cassettes. The study was supported by a grant from the Netherlands Prevention Fund.

1 Johnston CC, Hui SL, Wiske P, Norton JA, Epstein S. Bone mass at maturity and subsequent rates of loss as determinants of osteoporosis. In: DeLuca HF, Frost HM, Jee WSS, Johnston CC, Parfitt AM, eds. Osteoporosis: recent advantages in pathogenesis and treatment. Baltimore: recent advantages in pathogenesis and trea

2 Mazess RB. On aging bone loss. Clin Orthop Rel Res 1982, 165:239-51.

3 Riggs BL, Melton LJ. Involutional osteoporosis. N Engl $\mathcal{f}$ Med 1986;314:1676-86.

4 Gilsanz V, Gibbens DT, Carlson M, Boechat MI, Cann $C E$, Schulz EE. Peak trabecular vertebral density: a comparison of adolescent and adult females. Calcif Tissue In 1988;43:260-2

5 Krabbe S, Christiansen C, Rödbro P, Transböl I. Effect of puberty on rates of bone growth and mineralisation. Arch Dis Child 1979;54:950-3.

6 Landin L, Nilsson BE. Forearm bone mineral content in children. Acta Paediatr Scand 1981;70:919-23.

7 Specker BL, Brazerol W, Tsang RC, Levin R, Searcy J, Steichen J. Bone mineral content in children 1 to 6 years of age. Am $\mathcal{F}$ Dis Child 1987;141:343-4.

8 of age. Am $f$ Dis Child 1987;141:343-4. Vertebral bone density in children: effect of puberty. Radiology 1988;166: $847-50$.

9 Pollitzer WS, Anderson JJB. Ethnic and genetic differences in bone mass: a review with a hereditary vs environmental in bone mass: a review with a hereditary vs envi

10 Glastre C, Braillon P, David L, Cochat P, Meunier PJ, Delmas PD. Measurement of bone mineral content of the lumbar spine by dual energy $\mathrm{X}$-ray absorptiometry in normal children $=$ correlations with growth parameters f Clin Endocrinol Metab 1990;70:1330-3.

11 Trouerbach WTh, DeMan SA, Gommers D, Zwamborn AW, Grobbee DE. Determinants of bone mineral conten in childhood. Bone Mineral 1991;13:55-67.

12 Dalén N, Olsson KE. Bone mineral content and physical activity. Acta Orthop Scand 1974;45:170-4.

13 Chow R, Harrison JE, Notarius C. Effect of two randomised exercise programmes on bone mass of healthy postmenopausal women. BMF 1987;295:1441-4.

14 Cooper C, Barker DJP, Wickham C. Physical activity, muscle strength, and calcium intake in fracture of the proximal strength, and calcium intake in fracture

15 Krisa AM Black Sandler R, Cauley JA, LaPorte RE, Hom DL, Pambianco G. The assessment of historical physical activity and its relation to ad

16 Lau E, Donnan S, Barker DJP, Cooper C. Physical activity and calcium intake in fracture of the proximal femur in Hong Kong. $B M F$ 1988;297:1441-3.

17 Halioua L, Anderson JJB. Lifetime calcium intake and physical activity habits: independent and combined effects on the radial bone of healthy premenopausal Caucasian women. Am ₹ Clin Nutr 1989;49:534-41.

18 Wickham CAC, Walsh K, Cooper C, et al. Dietary calcium, physical activity, and risk of hipfracture: a prospective study. $B M \mathcal{F}$ 1989;299:889-92.
19 Matkovic V, Kostial K, Simonovic I, Buzina R, Brodarec $A$, Nordin BEC. Bone status and fracture rates in two regions of Yugoslavia. Am $\mathcal{f}$ Clin Nutr 1979;32:540-9.

20 Nilas L, Christiansen C, Rödbro P. Calcium supplementation and postmenopausal bone loss. $B M \mathcal{F} 1984$; 289:1103-6.

21 Black Sandler R, Slemenda CW, LaPorte RE, et al. Postmenopausal bone density and milk consumption in childmenopausal bone density and milk consumption in child-

22 Picard D, Ste-Marie LG, Coutu D, et al. Premenopausal bone mineral content relates to height, weight, and calcium intake during early adulthood. Bone Mineral 1988;4:299 309.

23 Matkovic V, Fontana D, Tominac C, Goel P, Chestnut II $\mathrm{CH}$. Factors that influence peak bone mass formation: study of calcium balance and the inheritance of bone mass in adolescent females. Am $\mathcal{F}$ Clin Nutr 1990;52:878-88.

24 Johnston CC, Miller JZ, Slemenda CW, et al. Calcium supplementation and increases in bone mineral density in children. N Engl f Med 1992;327:82-7.

25 Lloyd T, Andon MB, Rollings N, et al. Calcium supplementation and bone mineral density in adolescent girls ҰAMA 1993;270:841-4

26 DeMan SA, VanStiphout WAHJ, Grobbee DE, Hofman A Valkenburg HA. Is blood pressure in children related to physical fitmess? In: Oseid S, Morehouse CA, eds. Children physical fitness? In: Oseid S, Morehouse CA, eds. Children 1989;261-8.

27 Trouerbach WTh, Hoornstra K, Birkenhager JC, Zwamborn AW. Roentgendensitometric study of the phalanx Diagn Imag Clin Med 1985;54:64-77.

28 Bruce RA, Kusumi F, Hosmer D. Maximal oxygen intake and nomographic assessment of functional aerobic impairment in cardiovascular disease. Am Heart $\mathcal{F} 1973 ; 85$ 546-62.

29 Verschuur R, Kemper HCG. Habitual physical activity. Med Sport Sci 1985;20:56-65.

30 Lange Andersen K, Rutenfranz J, Masironi R, Seliger V. Habitual physical activity and health. Copenhagen: World Health Organization; 1978. WHO Regional Publ, Eur Series No 6 .

31 Hulshof KFAM, VanderHeiden-Winkeldermaat HJ, Kistemaker C, VanBeresteyn ECH. Calcium intake from dairy products. Assessment by semi-quantitative food frequency products. Assessment by semi-quan
method. Voeding 1989;11:302-6.

32 Food Information Office. Dutch food composition table. $31 \mathrm{~s}$ Rev Ed. The Hague: Food Information Office, 1983;33-6. Tanner JM, Whitehouse RH, Marshall WA, Healy MJR, Tanner JM, Whitehouse RH, Marshall WA, Healy MJR,
Goldstein H. Assessment of skeletal maturity and prediction Goldstein H. Assessment of skeletal maturity and prediction
of adult height (TW2 method). London, New York, San of adult height (TW2 method). Lo

34 Mazess RB, Barden HS. Interrelationships among bon densitometry sites in normal young women. Bone Mineral 1990;11:347-56.

35 Miller JZ, Slemenda CW, Meaney FJ, Reister TK, Hui S, Johnston CC. The relationship of bone mineral density and anthropometric variables in healthy male and female children. Bone Mineral 1991;14:137-52.

36 World Health Organization. Exercise tests in relation to cardiovascular function. Geneva: World Health Organization 1968. Technical Rep Series No 338.

37 Cumming GR, Everatt D, Hastman L. Bruce treadmill test in children: normal values in a clinic population. $A m ~ f$ Cardiol 1978;41:69-75.

38 Åstrand PO, Rodahl K. Physiological base of exercise. New York: McGraw-Hill Book Company, 1986

39 Saris WHM The assessment and evaluation of daily physical activity in children. A review. Acta Paediatr Scand 1985; Suppl 318:37-48.

40 Weber G, Kartodihardjo W, Klissouras V. Growth and physical training with reference to heredity. $\mathcal{F}$ Appl Physio 1976;40:211-5.

41 Kobayashi K, Kitamura K, Miura M, et al. Aerobic powe as related to body growth and training in Japanese boys: a longitudinal study. $\mathcal{f}$ Appl Physiol 1978;44:666-72.

42 Ekblom B. Effect of physical training in adolescent boys. $\mathcal{F}$ Appl Physiol 1969;27:350-5.

43 Eriksson BO. Physical training, oxygen supply and muscle metabolism in 11-13 year old boys. Acta Physiol Scand 1972;Suppl 384:1-48.

44 Gilliam T, Freedson P. Effects of a 12-week school physical fitness program on peak $\mathrm{VO}_{2}$, body composition and bloodlipids in 7 to 9 year old children. Int $\mathscr{f}$ Sports Med 1980;1:73-8.

45 Weymans M, Reybrouck T. Habitual level of physical activity and cardiorespiratory endurance capacity in children. Eur and cardiorespiratory endurance

46 Matkovic V, Heaney RP. Calcium balance during human orowth: evidence for threshold behavior. Am 7 Clin Nutr 1992;55:992-6.

47 Willet WC, Sampson L, Stampfer MJ, et al. Reproducibility and validity of a semiquantitative food frequency ques tionnaire. Am f Epidemiol 1985;122:51-65.

48 Morgan RW, Jain M, Miller AB, et al. A comparison of dietary methods in epidemiologic studies. Am $\mathcal{F}$ Epidemiol 1978;107:488-98. 